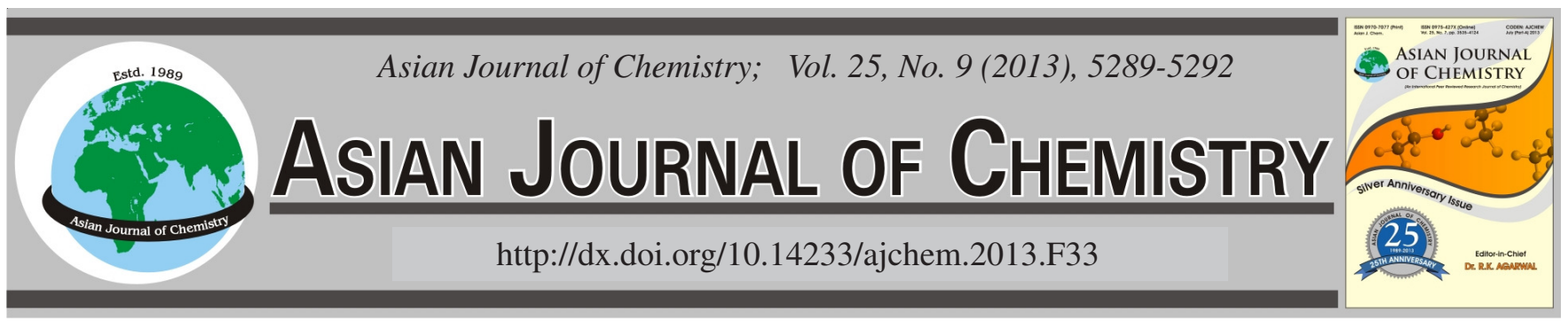

\title{
Characterization of Thermoplastic Elastomers Made of MAH- $g$-EPDM and ZnO Using Liquid-State NMR $\dagger$
}

\author{
Hyuk-Min Kwon ${ }^{1}$, Yeowool Kim ${ }^{1}$, Sung-Seen Chol ${ }^{1, *}, J_{\text {ong Woo BaE }}^{2}$ and Jung-Soo Kim ${ }^{2}$
}

\begin{abstract}
${ }^{1}$ Department of Chemistry, Sejong University, 98 Gunja-dong, Gwangjin-gu, Seoul 143-747, Republic of Korea
${ }^{2}$ Industrial Material Fusion Research Center, Korea Institute of Footwear and Leather Technology, Danggam-dong, Busanjin-gu, Busan 614-100, Republic of Korea
\end{abstract}

*Corresponding author: Fax: +82 2 34084317; Tel: +82 2 34083815; E-mail: sschoi@ sejong.ac.kr

AJC-13189

\begin{abstract}
Thermoplastic elastomers made of maleic anhydride-grafted ethylene-propylene-diene terpolymer (MAH- $g$-EPDM) and zinc oxide were characterized by liquid-state nuclear magnetic resonance spectroscopy. Organic materials remained in the samples were extracted and dried for nuclear magnetic resonance analysis. The samples were soaked in benzene and were put into a nuclear magnetic resonance tube. Sufficient deuterated chloroform was then added to the nuclear magnetic resonance tube. The ${ }^{1} \mathrm{H}$ and ${ }^{13} \mathrm{C}$ NMR spectra showed the characteristic peaks for the ethylene, propylene and diene units of ethylene-propylene-diene terpolymer. Raw and cured ethylene-propylenediene terpolymers were also analyzed and the results were compared with the thermoplastic elastomers. The analytical results suggested that the outside parts of MAH- $g$-EPDM did not participate in the formation of ionomers between the maleic acid groups of MAH- $g$ EPDM and zinc oxide. The outer parts might be composed of ethylene-propylene sequences and non-modified dienes not including maleic anhydride and maleic acid groups.
\end{abstract}

Key Words: Liquid-state nuclear magnetic resonance, MAH-g-EPDM, Zinc ionomer, Thermoplastic elastomers.

\section{INTRODUCTION}

Ethylene-propylene-diene terpolymer (EPDM) is one of the most versatile synthetic rubbers, which is made possible by adjusting its microstructure such as average monomer composition, sequence length distribution and diene type and concentration $^{1-6}$. Maleic anhydride-grafted ethylene-propylene-diene terpolymer (MAH- $g$-EPDM) is a useful way of compatibilizing immiscible polymer blends as well as improving interfacial adhesion in polymeric composites ${ }^{7-10}$.

Nuclear magnetic resonance spectroscopy is a useful analytical method for examining the molecular structures. Studies of solid-state NMR spectroscopy to examine elastomer networks have been reported ${ }^{11-13}$. Solid-state NMR is also a powerful technique for analyzing the crosslink density of a cured elastomer, because a chemical shift by crosslinking reflects the chemcal environment of surroundings of the crosslinked atoms ${ }^{14-16}$. On the other hand, compared to liquidstate NMR, it requires a relatively large amount of sample, long analysis time and expensive equipment. Liquid-state NMR has been used for characterization of polymeric materials. Pozzi and Marini ${ }^{17}$ analyzed polyethylene (PE)/polypropylene
(PP) blends using a high temperature liquid NMR. Choi et al. ${ }^{16}$ studied the relationship between the chemical shifts of swelling toluene and the crosslink densities of carbon black-reinforced natural rubber vulcanizates using liquid ${ }^{1} \mathrm{H}$ NMR. Khoee et al. ${ }^{18}$ analyzed the microstructure of styrene-butadiene rubber (SBR) using NMR.

Thermoplastic elastomers bridge the gap between plastics and rubbers and have a wide range of applications ${ }^{19-24}$. In this work, thermoplastic elastomers were prepared by mixing MAH-g-EPDM and zinc oxide and were analyzed by a liquid NMR to investigate their structural characteristics. Raw and cured ethylene-propylene-diene terpolymers were also analyzed and compared with the thermoplastic elastomers.

\section{EXPERIMENTAL}

Royaltuf 498 of Chemtura Co. was used as an MAH- $g$ EPDM and its ethylene, propylene, diene and maleic anhydride contents are 72.5, 25.5, 1 and $1 \mathrm{wt} \%$, respectively. KEP 510 and KEP 960 of Kumho Petrochemical Co. were used as an ethylene-propylene-diene terpolymer and their diene contents are $5.7 \mathrm{wt} \%$ and the ethylene contents are 71 and $70 \mathrm{wt} \%$, respectively. Three thermoplastic elastomers made of Royaltuf

$†$ Presented to the International Rubber Conference (IRC-2012), May 21-24, 2012, Jeju, Republic of Korea 
498 (100 phr), antioxidant (Songnox 1076, octadecyl-3-(3,4di-tert-butyl-4-hydroxyphenyl), $0.3 \mathrm{phr}$ ) and zinc oxide (1, 3 , or $5 \mathrm{phr}$ ) were prepared. A cured ethylene-propylene-diene terpolymer sample composed of KEP 960, filler and other ingredients was prepared. Tetrahydrofuran (THF), $n$-hexane, chloroform and benzene were purchased from Daejung Chemical and Metals Co. $\mathrm{CDCl}_{3}$ containing $0.1 \%$ tetramethylsilane was purchased from Aldrich Chemical Co.

Swelling ratios of the samples were measured by a swelling method. Organic materials remained in the samples were extracted and the weights of the organic materials-extracted samples were measured. They were soaked in swelling solvent (chloroform) for 3 days and the weights of the swollen samples were measured. The swelling ratio $(\mathrm{Q})$ was calculated by the equation of $\mathrm{Q}=\left(\mathrm{W}_{\mathrm{s}}-\mathrm{W}_{\mathrm{u}}\right) / \mathrm{W}_{\mathrm{u}}$, where $\mathrm{W}_{\mathrm{s}}$ and $\mathrm{W}_{\mathrm{u}}$ are the weights of the swollen and unswollen samples, respectively.

The liquid-state ${ }^{1} \mathrm{H}$ and ${ }^{13} \mathrm{C}$ NMR spectra were recorded at $500 \mathrm{MHz}$ using a Bruker Avance II 500 spectrometer (Germany) at $292 \mathrm{~K}$. The scan numbers of the ${ }^{1} \mathrm{H}$ and ${ }^{13} \mathrm{C} \mathrm{NMR}$ spectra were 16 and 1000, respectively. The samples were processed for the NMR analysis as follows. First, organic additives remained in the samples were removed by extracting with THF and $n$-hexane for 3 and 2 days, respectively and then the samples were dried for 2 days at room temperature. The sample strips were soaked in benzene and put into a NMR tube. Sufficient $\mathrm{CDCl}_{3}$ was added to submerge the strip.

\section{RESULTS AND DISCUSSION}

In the thermoplastic elastomers, ionic bonds can form between the carboxylic acid groups of MAH- $g$-EPDM and zinc oxide ${ }^{25,26}$. Fig. 1 shows ${ }^{1} \mathrm{H}$ NMR spectra of the thermoplastic elastomers. The peaks at 0.86, 1.09 and 1.27 ppm were assigned to methyl, methine and methylene groups, respectively ${ }^{19}$. The peaks at 0-2 ppm indicate saturated hydrocarbons, which are typical peaks of ethylene-propylene rubber (EPR) ${ }^{27,28}$.

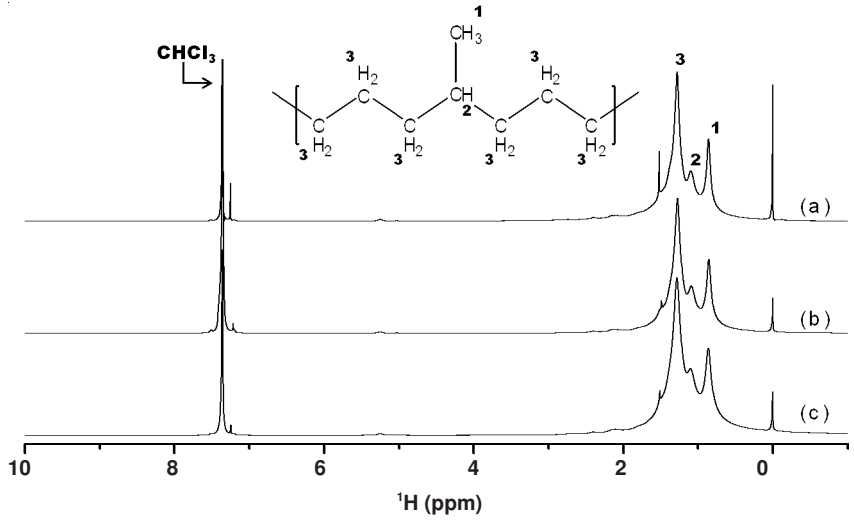

Fig. 1. ${ }^{1} \mathrm{H}$ NMR spectra of the thermoplastic elastomers containing $\mathrm{ZnO}$ of 1 (a), 3 (b) and 5 phr (c)

Fig. 2 shows the expanded ${ }^{1} \mathrm{H}$ NMR spectra (4.9-5.4 ppm) of the thermoplastic elastomers. The peaks at 5.02 and 5.25 ppm were assigned to diene ${ }^{28}$. The diene should originate from the MAH-g-EPDM. Maleic anhydride can react with the diene to graft to ethylene-propylene-diene terpolymer. Therefore, the detection of diene means that some dienes do not react with maleic anhydride. The raw ethylene-propylene- diene terpolymers were analyzed by liquid NMR to compare the thermoplastic elastomers. The ${ }^{1} \mathrm{H}$ NMR spectra of the raw ethylene-propylene-diene terpolymers also showed the typical saturated hydrocarbon peaks at 0-2 $\mathrm{ppm}$ and diene peaks at 4.9-5.4 ppm (Fig. 3).

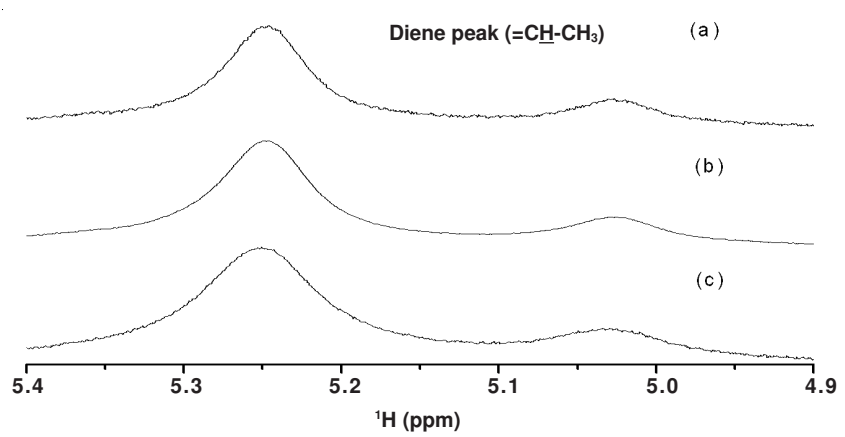

Fig. 2. Expanded ${ }^{1} \mathrm{H}$ NMR spectra (4.9-5.4 ppm) of the thermoplastic elastomers containing $\mathrm{ZnO}$ of 1 (a), 3 (b) and $5 \mathrm{phr}$ (c)

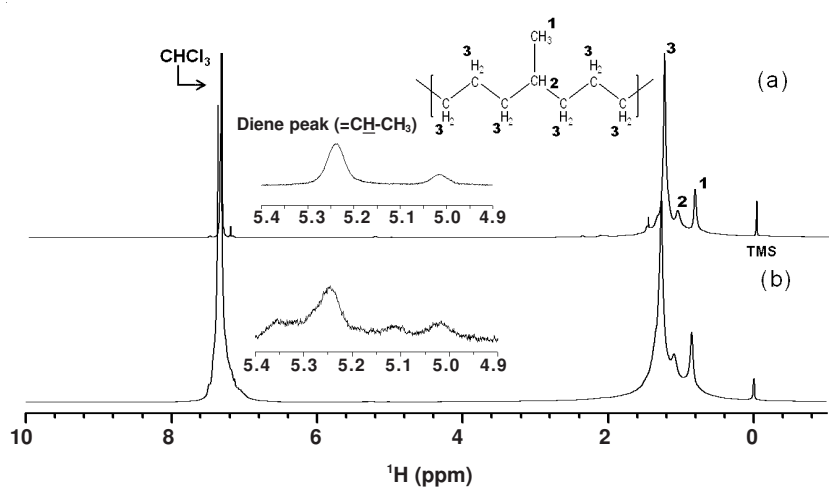

Fig. 3. ${ }^{1} \mathrm{H}$ NMR spectra of the raw EPDMs of KEP 510 (a) and KEP 960 (b)

In order to examine the existence of maleic acid groups of the MAH- $g$-EPDM, the ${ }^{1} \mathrm{H}$ NMR spectra were expanded in the range of 10-15 ppm (Fig. 4) because the hydroxyl group of maleic acid appears in the range ${ }^{29}$. However, there was no signal in the range of 10-15 ppm. Maleic anhydride groups can change to maleic acids by hydrolysis during the sample preparation. If these maleic acids react with zinc oxide to form ionic bonds, they will be bound to the zinc oxide particle. Relaxation of the bound maleic acids might be very slow, which results in no signal about the hydroxyl group. Therefore, the lack of a signal at $10-15$ ppm in the ${ }^{1} \mathrm{H}$ NMR spectra of the thermoplastic elastomers indicates the formation of ionic bonds between the maleic acid groups and zinc oxide.

\section{(a)}

(b)

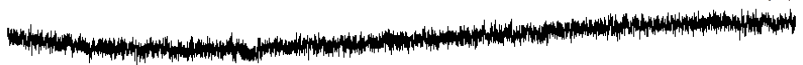

(c)

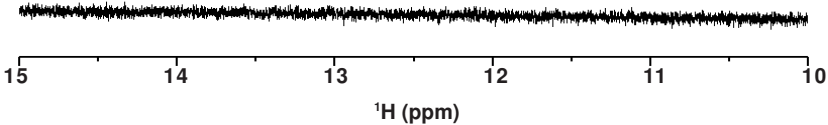

Fig. 4. Expanded ${ }^{1} \mathrm{H}$ NMR spectra (10-15 ppm, alcohol region of maleic aicd) of the thermoplastic elastomers containing $\mathrm{ZnO}$ of 1 (a), 3 (b) and $5 \mathrm{phr}(\mathrm{c})$ 
Fig. 5 shows ${ }^{13} \mathrm{C}$ NMR spectra of the raw ethylenepropylene-diene terpolymer and thermoplastic elastomers. The principal peaks were marked in the spectrum. The peaks at 19.7, 27.2, 30.1, 32.8 and 37.2 ppm were marked numbers 5, $3,4,1$ and 2, respectively. The number 1 peak at $32.8 \mathrm{ppm}$ was assigned to $\sim \mathrm{CH} \sim$, while the number 5 peak at $19.7 \mathrm{ppm}$ was assigned to methyl $\left(\mathrm{CH}_{3}\right)$. The other peaks of number 2, 3 and 4 peaks corresponded to methylene $\left(\sim \mathrm{CH}_{2} \sim\right)$. The peak at $29.8 \mathrm{ppm}$ was assigned to isolated $\mathrm{CH}_{2} \cdot{ }^{30-32}$ The saturated hydrocarbons of the MAH- $g$-EPDM are also clearly shown in the ${ }^{13} \mathrm{C}$ NMR spectrum of the thermoplastic elastomers as well as in that of the raw ethylene-propylene-diene terpolymer. On the other hand, no peaks about the carbonyl group of maleic acid or maleic anhydride were observed as shown in Fig. 6. In general, a carbonyl group peak in a ${ }^{13} \mathrm{C}$ NMR spectrum appears at $150-190 \mathrm{ppm}^{32}$.

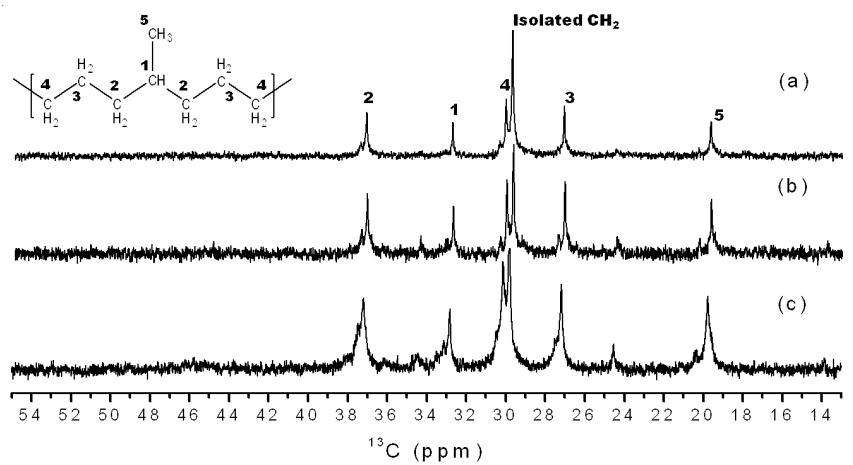

Fig. 5. ${ }^{13} \mathrm{C}$ NMR spectra of KEP 960 (a), the thermoplastic elastomer containing $\mathrm{ZnO} 1 \mathrm{phr}$ (b) and the thermoplastic elastomer containing $\mathrm{ZnO} 5 \mathrm{phr}$ (c)

(a)

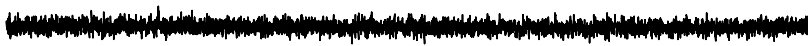

(b)

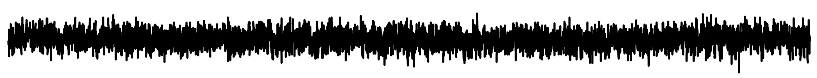

(c)

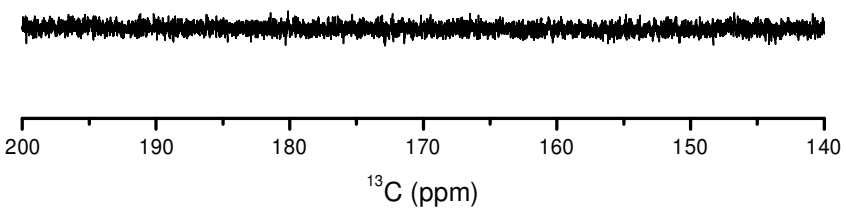

Fig. 6. Expanded ${ }^{13} \mathrm{C}$ NMR spectra (140-200 ppm, carbonyl group region) of KEP 960 (a), the thermoplastic elastomer containing $\mathrm{ZnO} 1 \mathrm{phr}$ (b) and the thermoplastic elastomer containing $\mathrm{ZnO} 5 \mathrm{phr}$ (c)

The cured ethylene-propylene-diene terpolymer sample was also analyzed. Organic materials remained in the sample were removed and the NMR sample was prepared using the same method for the thermoplastic elastomer analysis. Fig. 7 shows ${ }^{1} \mathrm{H}$ NMR spectra of the cured ethylene-propylenediene terpolymer sample. Unlike the ${ }^{1} \mathrm{H}$ NMR spectrum of the raw ethylene-propylene-diene terpolymer (Fig. 3), the peaks at 0-2 and 4.9-5.4 ppm assigned to saturated hydrocarbons and dienes, respectively, were not observed. This can be explained by the slow relaxation of polymer chains due to the high crosslink density. The cured ethylene-propylene-diene terpolymer has a number of sulfur crosslinks which leads to slow relaxation and there is no signal for ethylene-propylenediene terpolymer.

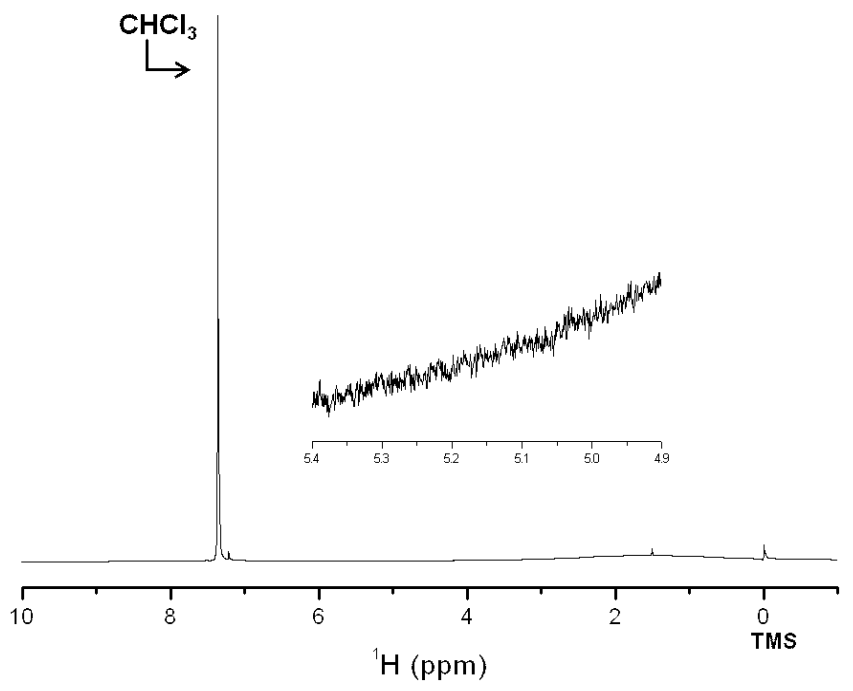

Fig. 7. ${ }^{1} \mathrm{H}$ NMR spectra of the cured EPDM

Swelling ratios (Qs) of the thermoplastic elastomers and the cure ethylene-propylene-diene terpolymer were shown in Fig. 8. The swelling ratios of the thermoplastic elastomers were much larger than that of the cured ethylene-propylene-diene terpolymer. This means that crosslink density of the cured ethylene-propylene-diene terpolymer was much higher than those of the thermoplastic elastomers. The swelling ratios of the thermoplastic elastomer decreased as the zinc oxide content increased. This indicates that crosslink density of the thermoplastic elastomer increased with increasing the zinc oxide content. Crosslink points in the thermoplastic elastomers are ionic bonds formed between the maleic acids and zinc oxide.

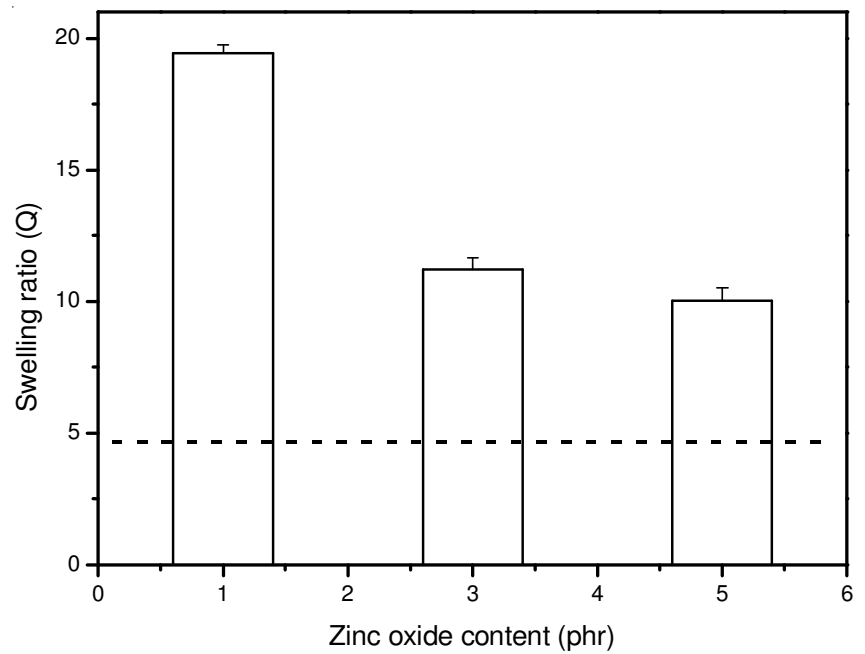

Fig. 8. Variation of the swelling ratio $(\mathrm{Q})$ of the thermoplastic elastomer with the $\mathrm{ZnO}$ content. The dashed line denotes the swelling ratio of the cured EPDM

The NMR analysis results showed that the thermoplastic elastomers have pseudo-crosslinks by ionic bonds between the maleic acids of MAH- $g$-EPDM and zinc oxide particles, 
some diene groups are not treated by maleic anhydride and the outside parts do not include the ionic bonds. Fig. 9 shows that the outer parts are composed of ethylene, propylene and unreacted diene units. Using liquid NMR, existence of the outside parts in the thermoplastic elastomer and unmodified dienes can be identified.

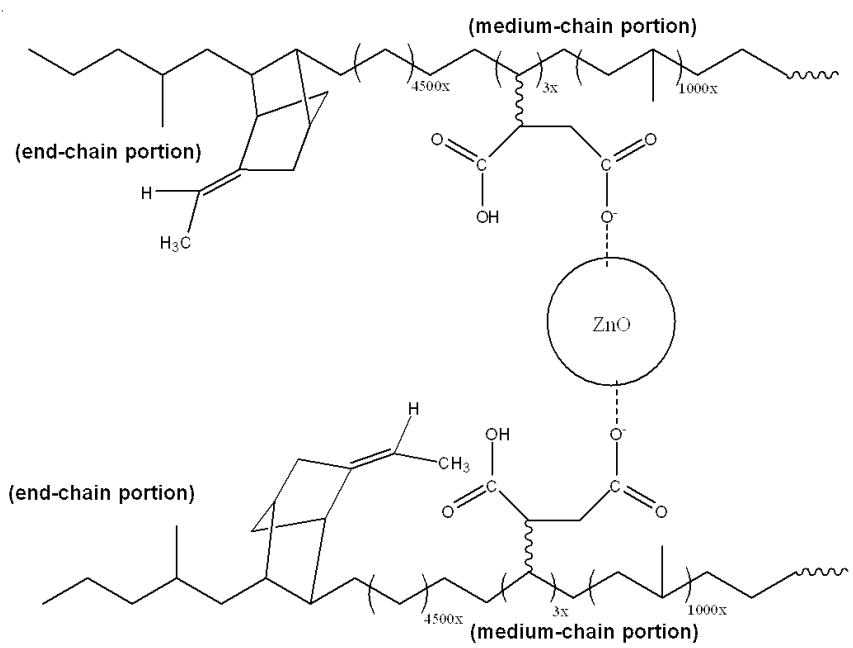

Fig. 9. Plausible ionomer structure of the thermoplastic elastomer

\section{ACKNOWLEDGEMENTS}

This research was supported by a grant from the Fundamental R \& D Program for Core Technology of Materials funded by the Ministry of Knowledge Economy, Republic of Korea.

\section{REFERENCES}

1. Q. Zhao, X. Li and J. Gao, Polym. Degrad. Stab., 94, 339 (2009).

2. Q. Zhao, X. Li, J. Gao and Z. Jia, Mater. Lett., 63, 1647 (2009).

3. S.-S. Choi, H.-S. Chung, Y.-T. Joo, K.-M. Yang and S.-H. Lee, Elastom. Comps., 45, 100 (2010).

4. K.H. Seo, K.-S. Cho, I.-S. Yun, W.-H. Choi, B.-K. Hur and D.-G. Kang, Elastom. Comps., 45, 212 (2010).

5. S.-S. Choi and O.-B. Kim, Elastom. Comps., 46, 138 (2011).
6. C.Y. Par and Y.-B. Hwang, Elastom. Comps., 46, 329 (2011).

7. J. Cha and J.L. White, Polym. Eng. Sci., 41, 1227 (2001).

8. M. van Duin and H. Dikland, Polym. Degrad. Stab., 92, 2287 (2007).

9. M. Ginic-Markovic, N.R. Choudhury, M. Dimopoulos, J. Matisons and C. Kumudinie, J. Appl. Polym. Sci., 80, 2647 (2001).

10. G.M.O. Barra, J.S. Crespo, J.R. Bertolino, V. Soldi and A.T.N. Pires, J. Braz. Chem. Soc., 10, 31 (1999).

11. J.H. O'Donnell and A.K. Whittaker, Polymer, 33, 62 (1992).

12. J.H. O'Donnell and A.K. Whittaker, Br. Polym. J., 17, 51 (1985).

13. A.E. Somers, T.J. Bastow, M.I. Burgar, M. Forsyth and A.J. Hill, Polym. Degrad. Stab., 70, 31 (2000).

14. V.M. Litvinov and A.A. Dias, Macromolecules, 34, 4051 (2001).

15. M. Garbarczyk, F. Grinberg, N. Nestle and W. Kuhn, J. Polym. Sci. Part B.: Polym. Phys., 39, 2207 (2001).

16. Y.K. Chae, W.Y. Kang, J.-H. Jang and S.-S. Choi, Polym. Test., 29, 953 (2010).

17. P. Pozzi and M. Marini, Polym. Test., 27, 161 (2008).

18. S. Khoee and M. Sorkhi, Polym. Eng. Sci., 47, 87 (2007).

19. K.-S. Lee, M.-C. Choi, S.M. Kim and Y.-W. Chang, Elastom. Compos., 45, 156 (2010).

20. E.J. Choi, J.H. Yoon, J.K. Jo, S.E. Shim, J.H. Yun and I. Kim, Elastom. Compos., 45, 170 (2010).

21. S. Saikrasun and T. Amornsakchai, J. Appl. Polym. Sci., 107, 2375 (2008).

22. C. Yi, Z. Peng, H. Wang, M. Li and C. Wang, Polym. Int., 60, 1728 (2011).

23. H. Wack, D. Hintemann, H. Michael and N. Buschner, J. Appl. Polym. Sci., 120, 1290 (2011)

24. D. Yamaguchi, M. Cloitre, P. Panine and L. Leibler, Macromolecules, 38, 7798 (2005).

25. S.R. Rafikov, Y.B. Monakov, I.A. Ionova, G.P. Gladyshev, A.A. Andrusenko, O.A. Ponomarev, A.I. Vorob'eva, A.A. Berg, L.F. Antonova, Ė.I. Ablyakimov, M.F. Sisin and A.A. Smorodin, Polym. Sci. U.S.S.R., 15, 2225 (1971).

26. J. Zhang, Q.-J. Ding, B.-X. Hu, B.-L. Liu and J. Shen, J. Appl. Polym. Sci., 101, 1810 (2006).

27. K. Doudin, A. Ahmad and S.A. Malaika, Polym. Degrad. Stab., 94, 1599 (2009).

28. A.O. Ramona, P.C.M.M. Magusin, V.M. Litvinov, M.V. Duin and M.A.J. Michels, Macromolecules, 40, 8999 (2007).

29. D.L. Pabia, G.M. Lampman and G.S. Kriz, Introduction to Spectroscopy, edn. 3, Chap. 3-4, pp. 119-234 (2007).

30. C.J. Carmen, C.E. Harrington and C.E. Wilkes, Macromolecules, 10, 530 (1977).

31. J.C. Randall, Macromolecules, 11, 33 (1978).

32. R. Winters, J. Lugtenburg, V.M. Litvinov, M.V. Duin and H.J.M. de Groot, Polymer, 42, 9745 (2001). 